\title{
Correction to: Mental health, subjectivities and forms of neuroscience: a critical realist examination
}

\section{David Pilgrim ${ }^{1,2}$}

Published online: 25 June 2019

(C) Springer Nature Limited 2019

\section{Correction to: Social Theory \& Health (2019) 17:140-157 https://doi.org/10.1057/s41285-019-00088-y}

This article was erroneously published in Volume 17, Issue 2 (2019) https://link. springer.com/article/10.1057/s41285-019-00088-y.

The article is now included in the special issue "Engaging experience: mobilising personal encounters with mental ill-health in social science" Volume 17, issue X (2019).

The original article can be found online at https://doi.org/10.1057/s41285-019-00088-y.

David Pilgrim

D.Pilgrim@soton.ac.uk

1 University of Liverpool, Liverpool, UK

2 University of Southampton, Southampton, UK 


\section{Abstract}

The examination of personal experience in human science has been highly variegated. At one end of a spectrum, strong subjectivists prioritise and privilege personal experience as an authentic marker of being human and as a window into our embedding social contexts. At the other end are neuro-reductionists, who explain (or even explain away) personal experience as merely an epiphenomenon of brain activity. With a focus on mental health and psychiatry, critical realism is used to explore this spectrum and it endorses a view that the brain affords our capacity to think, feel and act as human agents in contingent contexts but cannot ultimately explain any of these.

Keywords Neuroscience $\cdot$ Subjectivities $\cdot$ Critical realism $\cdot$ Biopsychosocial model

\section{Introduction}

This article works towards a discussion of neuroscience from a critical realist perspective, with a focus on mental health problems and psychiatric knowledge. Critical realism (CR) is a vehicle to resolve what might seem to be two irreconcilable positions. On the one hand, there are human scientists who emphasise us all being reflexive human agents in shifting social contexts. In this view, personal accounts are important research data and may even be privileged or sacralised as a priority in human science. On the other hand, some neuroscientists see the personal accounts we give of our lives as being reducible to brain activity. Neural events then are the research priority not personal experience.

$\mathrm{CR}$ accepts that our inner and outer forms of material reality create the conditions of possibility for us to be reflexive language-using human agents (ontological realism). And because we have these agential features of being human, it is important to understand how reality is experienced and represented across time and space (epistemological relativism). By holding onto the importance of both ontological realism and epistemological relativism (rather than attending only to one), we can think of the legitimacy and role of personal experience as being on a continuum. At one end of this spectrum is the allegedly 'disinterested' objectivist account of the neuro-scientific expert and at the other is the raw experience of psychiatric patients, unsullied and unmediated by the theories and clinical judgments of 'mental health professionals'.

At each point on the spectrum, we find personal accounts starting to constitute rhetorics of justification, which harbour different forms of reductionism. CR points up recurring errors in the latter regard. The first type of error is reducing one level of activity in our laminated reality in open systems to another one. Later I will argue that conventional neuroscience is crassly prone to this error. The second error type is the epistemic fallacy. That is when we confuse the map with the territory. We confuse what we call reality with reality itself; an example of this would be psychiatric nosologies, which assert that what the profession calls mental disorder is the valid reality of all disvalued behavioural deviations from social norms (about distress, unintelligibility and incorrigibility) across all times and places. 
As far as both of these errors are concerned, the collective personal experiences of professionals, as well as their patients, are relevant. We can think of these collective viewpoints as the rhetorics of interest groups. The subjective comes into play in mental health debates because all parties, whatever their positions, use forms of rhetorical authority, whether it is derived from science (scientism) or personal experience (epistemological privilege). These rhetorics are typically inflected by reductionist forms of reasoning, albeit with competing preferences about their content (Simons 1990).

Moreover, this is not only a clash of rationalities or discrepant forms of situated reasoning. The affective appeal in these rhetorics is also important. This emotional and sometime emotive character varies from the paternal sensibility and security, offered by medical science, to the conscience-satisfying appeal of holism and social justice, emerging from the 'lived experience' of disaffected psychiatric patients and a range of dissenting professionals inside and outside of psychiatry. Professional claims to objective science, bolstered by drug company money and the confidence borne of medical training, compete with those less convinced and preferring a focus on psychiatry as a pseudo-science and the iatrogenic and oppressive impact of its practice (e.g. Lakoff 2005; Herzberg 2009; Rose 2017). When considering reductionism and rhetoric, in the field of health research CR has relied upon the explanatory power of the biopsychosocial model. I will argue later that whilst this is an improvement upon the bio-reductionism common in medical science, it does not exhaust our task of understanding the errors of conventional neuroscience (see below).

The challenge of neuroscience orthodoxy is notable because of its hegemonic position in mental health policy. Bio-reductionism has been a perpetual theme within psychiatry, from its roots in eugenic psychopathology at the end of the 19th century to the 'Decade of the Brain' a century later (e.g. Guze 1989; cf. Jones and Mendell 1999; Pilgrim 2008). Countering this trend have been others wishing to argue that adversity and inequality, not biological vulnerability, is the best way to understand what, for now, we call 'mental disorder' (e.g. Read et al. 2014; Anda et al. 2006; Schilling et al. 2008; Cutajar et al. 2010).

One aspect of the tension between bio-reductionists and their critics has been the role we afford to personal authority. The clinical experience of professionals is pitted against the 'lived experience' of patients (an epistemological matter). The other aspect though is that those competing rhetorics imply different assumptions about causality (an ontological matter). This leaves us with the legacies of two distinct philosophical traditions embedded in forms of debating rhetoric (Margolis 1990). The focus on personal authority (from either mental health professional or 'experts by experience') reflects idealism: forms of mind-dependent reasoning. The focus on evidential claims of biological, psychological or social determinism reflects forms of realism, which assume a mind-independent reality.

With the above introductory points in mind, the article proceeds, from a CR perspective, to consider the role of different forms of reductionism in their mental health policy context; the strengths and limitations of the biopsychosocial model as a definitive alternative to bio-reductionist medical science; and the possibility of a non-reductionist role for neuroscience. 


\section{Forms of reductionism in a context of terminological and policy confusion}

One recurring source of confusion in debates about causes and meanings within mental health debates is that the vast discursive range of 'mental health' is a cue for discussing not only well-being but also distress, unintelligibility and incorrigibility. The latter have been codified by psychiatry as 'the neuroses', 'the psychoses' and 'the personality disorders' (Pilgrim 2015a).

Terminological confusion is rife in this arena of health research compared to physical diagnoses, even if the latter are not totally problem-free (Pilgrim 2007). We might hear lay people, politicians and even professionals themselves, at times, talking vaguely of 'mental health problems' (a problem to whom and why?) or 'mental health issues' (an issue from where and for what reason?) and even the dubious logicality of 'mental health illnesses' and 'mental health diagnoses'. Maybe in retreat from the anxiety-laden contention about the term 'mental illness', these euphemistic inversions create more, not less, confusion. Any discussion of what used to be taken for granted as 'mental illnesses' (our traditional medically dominated $d o x a$ ) is now characterised by imprecision and emergent but unchecked taken-for-granted meanings that are even deployed at times by wellinformed commentators.

Maybe when a field of debate is so confused and confusing, reductionist certainties move in as offered correctives. It is as if the less we really understand or agree upon, the more that we are prone to talk in generalities, which are vague but also give a premature or unwarranted sense of certainty. Examples here include the idea that psychotropic medication compliance predicts symptom control, when actually this is hit and miss within and between cases. Another example is about investing more in mental health' i.e. more money promised from politicians, typically to 'deliver' more of what is already on offer: more staff, beds and currently preferred medicinal and conversational interventions. This technological intervention paradoxically assumes that more failure is now suddenly going to become a success. Also, 'early identification and accurate diagnoses' become harbingers of progress, despite their implications for premature stigmatisation and the iatrogenic implications for immature brains. Other reductive headlines recur about more 'care packages in the community', 'recovery', 'evidence-based practice' and 'co-production'.

Reductive technological policy fixes are offered, about a vast panoply of complex and contested socio-existential matters, by political and professional leaders, who have in the past clearly failed within their own terms. In the case of mental health policy, 'the technological fix' is constantly promised but rarely materialises in its practical impact (Sarewitz and Nelson 2008). If the medicinal paraphernalia of psychiatry, backed up with lawful forms of compulsory treatment and drug company marketing, have been so effective, then why are 'relapse' and 'treatment resistance' so common and why does the prevalence of mental illness increase not decrease in Western societies?

By the end of the 20th century after over a hundred years of psychiatric medicine, 'mental health services' were neither 'kindly' nor 'efficacious', to use the criteria 
applied by Peter Sedgwick in his critical review of both the mental health industry and the 'anti-psychiatrists' who attacked it (Sedgwick 1982). By the turn of this century, there was an epidemic of medicinal prescribing, with $10 \%$ of the Western population now taking anti-depressant medication. That recent history has not witnessed a reduction in identified mental disorder in society, quite the contrary; the epidemic of prescribing has not diminished the measured prevalence of mental disorder but the reverse (Whitaker 2010).

Not only do psychotropic drugs tranquilise and manipulate mood, rather than cure the complexities of distress and personal dysfunction, situated in particular biographical and social contexts, they create adverse effects (not 'side effects' implying triviality of impact) that are often life diminishing and sometimes life threatening. At times their therapeutic effects barely perform better than placebos but they expose all of their recipients to clinical iatrogenesis (Kirsch 2009; Breggin and Breggin 1994). These purported fixes have not worked because they have been reductionist wild goose chases. Biological reductionism has provided no advances in clinical practice for psychiatry (Kingdon and Young 2007). Despite this poor showing of medicinal solutions to psycho-social complexity, some patients may report benefits and seek diagnoses and comply with medical prescriptions. For example, up to a third of women taking antidepressants consider them beneficial and they accept the (unproven) chemical imbalance view of their distress (Fullagar 2009).

Given that some patients are very hostile to psychiatric orthodoxy and others seemingly compliant, professionals might be invited then to stop and reflect rather than rushing in with their offers of more of the same. One starting point for that reflection is the precarious hegemony of psychiatric diagnosis and its attendant biomedical treatment routines. Those nosologies have been queried both inside and outside of psychiatry and a wide set of competing claims for legitimacy have come from psychologists, sociologists and disaffected patients (Pilgrim 2007; Moncrieff 2008). Given this range of views and contestation, with no ready explanations to hand much of the time, this is a large playground for competing claims, some of which are over-inclusive and even grandiose. That very lack of a clear consensus about causes and meanings (and even agreed terminology noted above) creates a space for strong reductionist claims.

The latter might be narrowly behavioural. Some learning theorists have claimed that all mental health problems are explicable by reference to some combination of classical and operant conditioning (Yates 1970; Skinner 1971). But at the very time that behaviourism was claiming its hegemonic status within academic psychology during the mid-20th century, deep subjectivists disagreed. Here for example the existentially orientated psychoanalyst, Ronald Laing, made the point that:

The relation between experience and behaviour is the stone that the builders will reject at their peril. Without it the whole structure of our theory and practice must collapse. (Laing, 1967: 21)

Maybe then a skilled training in Laingian psychotherapy might now account for and ameliorate everything we might call a 'mental health problem'. Maybe instead we might opt for mental health problems being simply a linguistic matter and focus our attention on discourses and even discourses on discourses (Rose 1990; Lemert 
1980). If this postmodern reduction does not suit we might fall back on genetics, e.g. schizophrenia is a genetically determined illness. Such a view predominated in German psychiatry and was intertwined with a eugenic orthodoxy in Europe and North America in the first part of the 20 century and it has strong resonances still today (Pilgrim 2008).

Set against all these professional accounts inside and outside of psychiatry, we might opt for the epistemological privilege of those in receipt of diagnoses and treatments. These 'experts by experience' (or those with 'lived experience') could make a claim to provide the definitive account. Within the latter, a traumagenic model of causation has found favour recently; all or most mental health problems might be accounted for by childhood adversity or more recent forms of environmental insult. It is only what has happened to people that matters not their constitutional vulnerability; the favoured assumption of eugenic Kraepelinian psychiatry (Johnstone and Dallos 2006).

This range of competing sources of authority seems to be offering us a range of options but they are all in their own way prone to reductionism (biological, psychological or social), with linguistic reductionism being offered within some psychological and sociological accounts. To be clear, reductionism does not necessarily mean that an argument may not legitimately signal a tendency or demi-regularity (e.g. trauma causing distress, dysfunction or unintelligibility). What reductionism does though is produce unwarranted generalisations and identifies causality at only one level of complex reality in open systems, and all human conduct is an expression of the latter.

The specific risk of linguistic reductionism is that lived experienced is sacralised: it is afforded the power not merely to express authentically the plight of being a psychiatric patient but it also offers us a superior explanatory account of mental abnormality to that offered by professionals. This risk of wrongly assuming that the epistemological privilege of social actors (in this case psychiatric patients) gives us a comprehensive insight into the complexity of emergence of their experience is summarised here by a leading CR sociologist Margaret Archer:

....we do not identify structures by interviewing people about them.....In falsely privileging the discursive penetration of agents (we fail to distinguish between) structures, their causal powers and their social reception.' (Archer, 1997:177)

If patient accounts are not to be over-valued, despite the appeal of their epistemological privilege, then professional rhetoric is particularly suspect because of the privilege it generates in relation to salaries, status and dominance in society about claimed medical authority. Two noteworthy claims of grand personal authority from psychiatry, about DSM-5, came from the Chair of the DSM-IV Committee (Frances 2010) and from a bullish neuro-reductionist, Thomas Insel. The latter is a former Director of the National Institute of Mental Health in the US and he issued a statement that DSM-5's lack of connection to neuroscience was its core problem that must now be corrected by basic brain research (https://www.nimh.nih.gov/about/ directors/thomas-insel/blog/2013/transforming-diagnosis.shtml).

Frances and others considered that functional psychiatric diagnoses were fine in principle but we could have too much of a good thing. On that point see also Angel (2011) and Wykes and Callard (2010). By contrast, Insel told us that only brain 
disorders and evidence of their underlying neural dysfunction should be the basis for scientific progress. What Insel was in no doubt about was that all the symptoms under the headings of functional diagnostic categories, such as depression or schizophrenia, were traceable unarguably to brain disorders. We just need to wait for the right sort of evidence to confirm this assumption. This epistemic fallacy of a priorism from Insel is present in neuroscience more generally (see below) and replays the view of Freud that ultimately mental illness would be reducible to faulty brain mechanisms; what Wolman (1981) called 'hoped-for-reductionism'.

But this cool claim to scientific authority from versions of medical traditionalism (even in the absence of evidence) was not left untroubled. For example, dissenting voices from patients and critical professionals preferred in their rhetoric of justification to attack biomedical authority. Hostile slogans appeared on social media in response to the old eugenic consensus and new hoped for reductionism of neuroscience. Biomedical psychiatry was being held in total contempt, not honoured for its achievement of scientific progress. Here is an example from social media:

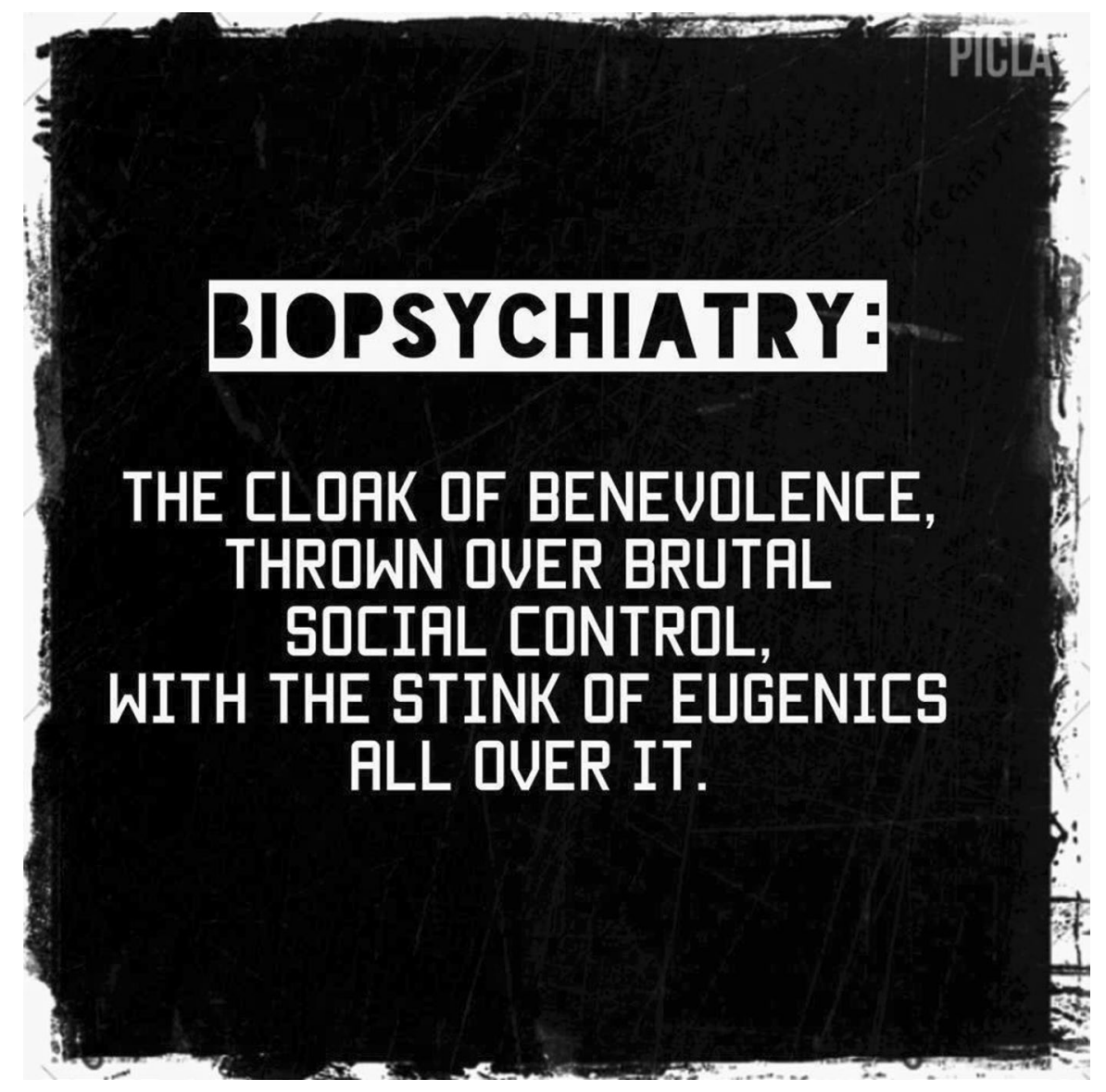


In the midst of these competing rhetorics, all sides are reflecting a common characteristic. The hoped-for-reductionists, like Insel at one pole of the spectrum of debate, and the epistemological privilege being claimed at the other by those of 'lived experience' have emerged from determined and determining beings. Insel appealing to the final authority of neuroscience is reliant on faith not knowledge. $\mathrm{He}$ is a successful product of his medical socialisation and the current appeals of a special status in a vulnerable medical speciality (psychiatry). He is a moral agent, but one shaped by these past and current social processes. For their part the most powerless of all (psychiatric patients), who are discredited in society so often for their very lack of reason, now must rescue their authority. The trump card of 'lived experience' can be shored up at times by a plausible claim to understanding causation: 'the traumagenic model'. The different approaches to causation reflect the preferred interests of the two groups. The professional orthodoxy of bio-determinism satisfies the interests of psychiatry as a medical specialty with weak legitimacy. The explanatory preference for contingent adversity from critical service users and some professionals reflects a need for biographies to be respected. Put differently, claims about generative mechanisms reflect the collective and political a priori interests of each group.

This is a cue to turn to critical realism and the cautious application of a biopsychosocial model in mental health. The rhetorics of justification from the neuroscientific assumptions on one side and environmentalist claims from those (both professionals and patients) favouring traumagenic or broader environmentalist explanations for mental health problems on the other are ontological matters. They both claim that there are real causal antecedents or generative mechanisms in the emergence of the symptoms of what are called 'mental disorders' (i.e. versions of distress, unintelligibility or incorrigibility). (Note that some research integrates the testimonies of trauma with epigenetic and neurochemical changes during child development, see later). What all these claims have in common is that they are epistemological matters even though they differ. The neuroscientists talk of models of neural action in closed systems of the brain and the radical service users talk of their understanding of surviving adversity in the past and present in the open system of their unique biographies.

Finally ethical matters are implied in these rhetorics, but with the neuroscientists supporting traditional medical paternalism (i.e. the right and obligation to treat mental disorder, if needs be coercively) and their opponents arguing for the need to be free from that paternalistic social control (i.e. the right to be supported and respected, when seeking help, but left alone otherwise). Moreover, given that the most controversial aspect of mental health work is about coercive treatment and deprivation of liberty without trial, the personal experience of identified patients takes on a particular salience. As well as making a contribution to a new social movement, they are anthropological testimonies to the exercise of power, which is often experienced as oppressive (Campbell and Rose 2011).

Thus although the rhetorics may be politically at odds with one another, they do share some common core foundational features that critical realism puts centre stage: ontological realism, epistemological relativism, and judgmental rationalism (Bhaskar 2016). In different ways they are making claims about the ontology 
of psychological difference in society (biologically versus biographically caused). They are also offering different claims to epistemological authority about these states (the view of the professional versus the view of the patient). In addition, they are making a value-based claim about human rights or human improvement (the professional's right to treat, if needs be coercively, versus the patient's right to be free but supported voluntarily and empathically).

\section{Critical realism and the cautious endorsement of the biopsychosocial model}

One favoured resolution to the above tensions from critical realists has been to support the deployment of the 'biopsychosocial model' (BPS model), because the latter attempts to address both causes and meanings. It might transcend the division between medical science and its hopes for explanation (erklären) and the more modest social scientific reliance on the description and interpretation of inter-subjective perspectives and meanings (verstehen) (Bhaskar and Danermark 2006; Williams 1999; Higgs et al. 2004).

Although the BPS model is now favoured in medical training (especially in general practice) and its promise of holism is appealing to many professionals and patients, its life began, significantly, in psychiatry. The work of Adolf Meyer at Baltimore in the first part of the 20th century started the ball rolling about nonreductionist aetiological accounts of mental illness but it was formally codified by George Engel in psychosomatic medicine (Meyer 1952; Engel 1980). This inclusive approach to aetiology and pathogenesis, doing its best to include a multi-factorial picture derived from biological, psychological and social factors, was a resistance within the profession of medicine to crude biomedical reductionism. It was not a wholesale attack on medicine at all, merely an appeal for a non-reductionist 'new medical model' (sic) (Engel 1977). By attacking bio-reductionism within the profession, Engel was reforming medicine for its own benefit. He was not indulging in a full-blown critique of medical theory and practice; what Illich (Illlich 1977) scorned as a 'domineering moral enterprise' in society.

The holism promised in the BPS model encouraged its endorsement within critical realism. However, this confidence has also been challenged by some sharing the philosophy. Pilgrim (2015b) argues that whilst the BPS model is ontologically inclusive about a laminated reality, which suggests multiple mechanisms operating synergistically to produce health outcomes, it is epistemologically naïve. After all it is a model not theory; it has a limited range of authority about how diseases emerge. It has no critical reflexivity about its own context. Where did medical concepts come from and do they bring with them power over others (patients and subordinated professions)? Is the medical profession entangled with the interests of others, such as the drug companies, that favour a magic bullet approach to diagnostic related groups? (In the context of this paper this question is rhetorical.) And what of the role of lay knowledge does it concur with, or dissent from, medical knowledge?

Engel's work did not offer reflexivity about to answer these questions. In other words, the BPS model encourages a more sophisticated approach to clinical insights 
to work out why this particular patient is presenting with these particular problems at this particular time in their life but it lacks social and political 'outsight'. Indeed some have argued that even the very minimal start of outsight expected from the social layer of the BPS model has not been delivered. Read (2005) complains that in the hands of psychiatric medicine, the BPS model has actually become a 'bio-biobio model'. It is also the case that medical publications purporting to utilise the BPS model do not acknowledge that medical knowledge itself reflects interest work and so is prone to the epistemic fallacy (e.g. Garcia-Toro and Auirre 2007).

To conclude this section, we can say that, from a critical realist perspective, the BPS model is ontologically sophisticated but epistemologically naïve. This leaves it with an under-developed potential for critical realists; it is certainly already an improvement on bio-reductionism, but it needs further development to be truly persuasive. However, even its legitimate exploration only of the complexities of causal antecedents prompts particular questions about neuroscience. The latter par excellence has re-asserted a set of biomedical certainties. These untenably reduce action (an agential aspect of being human) to behaviour (a mere mechanistic aspect of being an unthinking organism) (Archer 2000). Because of the offence created by neuro-reductionism, anti-positivist researchers and disaffected service users (not necessarily aware of abstract philosophical discussions) may be prone to reject neuroscience, in its entirety, when condemning it as the most recent example of biomedical reasoning within neo-Kraepelinian psychiatry. The next section argues that whilst such a suspicion is understandable, a revised form of holistic and emancipatory neuroscience may still be possible.

\section{Critical realism and neuroscience}

The discussion of the BPS model points to a specific challenge about understanding neuroscience, both in its general role in human science and in its specific claimed totalising application to 'mental disorder'. At its most basic, neuroscience is about mechanisms in the brain and nervous system. In principle, this is not problematic from a CR perspective at all. What becomes problematic is when those mechanisms are then afforded a singular causal authority about thought, feelings and human conduct, which excludes or precludes human agency in open systems. That distinction is made by Tortorello (2017), who notes two versions of brain science. The first is derived from positivist biology and Tortorello cites Francis Crick in that tradition:

You, your joys and your sorrows, your memories and ambitions, your sense of personal identity and free will, are in fact no more than the behaviour of a vast assembly of nerve cells and associated molecules. You are largely the behaviour of a vast population of neurons (Crick 1994: 3 cited in Tortorello 2017: 236)

This tradition is certainly realist. However, it is a form of naïve realism because it is without reference to human agents, who attribute specific meanings to events in their unique biographical contexts (what CR calls their 'concrete singularity'). This reductionism fails to grant a valid role for the emergent qualities of thoughts, 
feelings and reflections that comes with being not merely a sentient being but also a human being. It may well be that the human species and others (even arguably some machines) share aspects of intentionality and teleology (Dennett 1984) but humans have elaborated specific capacities of reflection. As a consequence, they do not simply 'behave' they also conduct themselves in moral orders that they contribute to, are mindful of and may times try to change. This emergent point about human capacity is endorsed by critical realists (e.g. Bhaskar 2016; Archer 2000) and is built upon a tradition in philosophy that confirms our special forms of reflection and intention that come from evolution; see for example from psychology Wolman (1981) and Broad (1925), as well as reviews of the philosophical trope of 'emergentism' in Clayton and Davies (2006). Other animals certainly think, feel and express intentions but the emergence of language-use creates a qualitative shift in those tendencies in humans.

The risk of confirming and affirming these emergent qualities of being human is that they are celebrated to a point of sacralisation, bringing with it the problem now of psychological rather than biological reductionism. However, notwithstanding that Laing, cited earlier, could be accused of psychological reductionism (by privileging the relationship between experience and behaviour) the triumphalist neuroscientific orthodoxy focuses on biological reductionism (the relationship between brain and behaviour). It offers the positivistic promise of brain science comprehensively explaining human conduct across all times and places (the false assumption of 'empirical invariance'). Insel's hoped-for-reductionism epitomises this positivistic tradition, expressed through the interest work of the biological disciplines in general and the particular interest work of medicine to retain its dominance over patients and subordinated healthcare professions.

Bhaskar (2016), and in previous work, points out that such a positivist tradition in science is derived from the assumptions of Parmenides that the world is a set of fixed processes given by the gods. According to that view, the duty of science was to discover the presumed lawful character of those relationships that were deemed in advance to simply exist in perpetuity and require incremental fathoming. By contrast, critical realists are within the tradition of Heraclitus, who said that 'a man cannot step into the same river twice for fresh waters ever emerge around him'. This implied flux, not fixity to be discovered in permanent god given laws in the universe. Moreover, his dictum about the man and the river implied that both changed over time and that the man as an agent chooses to step into the river (or not) and experience its particular character at a particular time (and might re-construe them later). The deceptively simple adage from Heraclitus contains all of the elements now proposed by critical realists: reflective human agents operate in a real complex and ever-shifting context; they are both determined and determining beings. This is what creates a break from positivist brain science.

That more complex view of people as determined and determining beings is offered by Varela (2003) and Harré (2002), Tortorello's second version of brain science. In their view, the brain affords our capacity to be human agents but our conduct cannot be reduced to one or more brain mechanisms. When our brain is impaired, then this certainly impacts our agency (for example the impaired choices of the dementia patient, who is disorientated in time and space). However, we cannot 
work back from behaviour to identify brain mechanisms readily. Varela gives the example of a man trembling at his daughter's wedding. It could be a Parkinsonian symptom or he could be overcome with pride and nostalgia about someone he loves. If trembling cannot be reduced predictably to a neural pathway, then there is little chance that the complex social-existential states, we call 'mental disorders', will be reducible to brain activity. Thus, a CR-endorsed version of neuroscience would necessarily reflect the importance of the role of personal experience and human agency, without sacralising it or endorsing psychological reductionism.

Given that brain science is not inherently and necessarily reductionist (as long it follows the strictures of those like Varela), then how has it actually fared to date in mental health policy formation? The answer is that it has by and large followed the first path of positivism and with it the attendant risk of closed system reasoning, the false assumption of empirical invariance and the deletion of human agency. Unlike the eugenic model of Kraepelin and his followers during the first half of the 20th century, is not merely a psychiatric enterprise but is an inter-disciplinary field. It draws on the allegiance of many in neurology, biochemistry, psychology, physiology, philosophy, as well as psychiatry.

However, during the second half of the 20th century the clinical professions became particularly interested in learning from and contributing to its topics of investigation. The inter-disciplinary range was consolidated during, the 1960s with the arrival of the International Brain Research Organisation, the International Society for Neurochemistry, the European Brain and Behaviour Society and the Society for Neuroscience.

Critiques of neuro-reductionism have come from neuroscientists themselves. For example, the physician and poet Tallis (2011) has highlighted what he calls the 'neuromania' that explains away culture and human conduct by referring to neural functioning alone. Neuro-reductionism has emerged in a context in which politicians can individualise complex social problems and thereby erase the testimonies to adversity offered by those endorsing the traumagenic model discussed earlier. Mental disorder rooted in brain mechanisms excludes the need to examine too closely the pathogenic impact of child sexual abuse, poverty, domestic violence, insecure employment, racism or bullying in schools and workplaces (Rose and Rose 2012). Moreover, neuro-reductionism itself has a direct market potential for the drug companies and might rejuvenate the flagging efficiency and profitability of psychotropic medication (Healy 2004). Thus, the neuroscience industry operating with a naïve 'brain causes behaviour' form of biological positivism serves several interests in its highly flawed logic.

The latter logic found favour within a progressive, not just conservative, Western polity. As well as George Bush (Senior's) 'Decade of the Brain' in the 1990s, Barak Obama in 2013 promoted the 'Brain Research through Advancing Innovative Neurotechnologies (BRAIN)' initiative. Similarly the political tendency to rely on neuroscience as a source of solutions to complex psycho-social problems has been evident in the policy preference expressed in the European Union's 'Human Brain Project '(HBP) (HBP-PS Consortium 2012). Here the core message and logic of the latter is cited that intends to decouple the brain from human agents and their particular social contexts: 
The evolutionary function of a brain is to control the organisms' behaviour in their environment. In principle, therefore, the only way to test or characterise the high-level behavioural or cognitive capabilities of a brain model is to create a closed loop between the model and a body acting in an environment and to interrogate the model through well-designed experiments ... Once a set-up has successfully replicated we can then identify causal mechanisms by lesioning or manipulating specific brain regions, transmitter systems, types of neuron etc. (ibid: 49, emphasis added)

In other words, neuroscience in its naïve but orthodox form deliberately sets out to study isolated or closed systems experimentally and focuses singularly on causality at the micro-biological level. This is anti-logical and anti-scientific because all human action operates as, and within, an open system and so this bioreductionist orthodoxy fundamentally misunderstands its own object of inquiry (Mingers 2011). It confuses methodological neatness with scientific competence and so its findings will be worthless, except over a limited range of neurological conditions. And even in the latter case (such as forms of dementia or inherited conditions like Huntingdon's Chorea) the person still remains with their particular biography and their embedding social context, including the continued affirmation of their personhood from others. This history and current situation will inflect their quality of life in their concrete singularity.

As for functional disorders, naïve neuroscience has leapt far ahead of its own evidence base. Its hoped-for-reductionism means that it already claims, without proof, that what we now call 'functional psychiatric disorders' are self-evidently brain disorders. The HBP report (ibid: 98), in an act of faith not science, designates mood disorders, psychotic disorders, anxiety disorders and addiction as being brain diseases. Taking for granted that all psychiatric conditions are brain disorders has even become an unfounded epidemiological assumption (see Wittchen et al. 2011).

This begs an ironical question: which faulty brain mechanism is causing those like Insel, Wittchen and the authors of the HBP report to reason so illogically and to have no insight into their behaviour? The answer of course, as with the patients they study, lies not in their brains but in the psycho-social context that has made their ways of thinking possible. That context includes the rhetorical desire to promote a particular way of reasoning that has arisen from interweaving political, professional and commercial processes, which the protagonists may or may not acknowledge consciously. As with their patients, their brains afford them the capacity to see, and speak about, the world in a certain way but their professional ideologies and interest work are not caused by those brains. Instead those supra-personal features exist in the materiality of the social processes that they have both inhabited and contributed to.

However, if we turn to the second version of neuroscience offered by those like Varela and Harré, and supported recently by some post-Foucauldian writers like Rose (2013), then there is no opposition between social and biological science at all. Despite many years of alienation between sociology and biology, a reconciliation was grudgingly made by the former (Benton 1991) and this trend has been 
reinforced by those examining epigenetic interactions in biosocial systems (Landecker and Panofsky 2013) and some sociologists who are trying to create a space where biology and sociology are not mutually exclusive (Fitzgerald et al. 2016).

To make a few obvious points flowing from this second way of doing neuroscience. First, we now know that environmental impacts in the womb and in infancy shape gene expression (e.g. Galea et al. 2011). Second, chronic social stress and acute trauma have direct impacts on neurotransmitters throughout the life span, for example simply by being raised and living in a city environment (e.g. Lederbogen et al. 2011). With regard to both of these points, we can note that such empirical findings can be recruited to defend either reductionist or non-reductionist neuroscience; it depends on whether or not personal accounts of ordinary people are afforded that role of the testimonies of human agents, rather than merely being sources of information for scientists and clinicians. (Logically, they could of course be both but the political preference for one or the other reflects the interest work of orthodox psychiatric professionals and their critics.)

Third, some unambiguously chronic biological states, such as diabetes, can affect emotional well-being and mood states (e.g. De Groot et al. 2016). Fourth, conscious strategies learned in psychological therapies or other planned practices like meditation or exercise can alter brain functioning and affect well-being (e.g. Erickson et al. 2015). Fifth, childhood adversity increases the risk of the experience of all symptoms subsumed by diagnostic categories (e.g. Cutajar et al. 2010). Sixth, the material contingencies of life (especially poverty and warfare) affect both our physical and mental health and so holism is demanded; reductionism is a threat to that inclusive form of academic inquiry.

On this last point we know that external social conditions are an important source of pathogenic influence (the causal interactions of warfare, child sexual abuse, poverty, racial and gender discrimination, domestic abuse, etc.). Moreover, the latter have variable subjective consequences in their interactions, i.e. intersectionality (Rosenfield 2012). Part of our subjective response might be to affirm our intersecting identities, as examples of random and unfortunate afflictions on the one hand, or recognise ourselves as victims of identifiable oppression that might spark resistance on the other (and subjective stages in between). (Intersectionality remains an ambiguous field of inquiry with merging identities at its centre and varying assumptions about external conditions affording their emergence; for a review of the topic from a CR perspective see Flatschart 2017).

Our contingent social contexts are also normative and so they set the parameters about what is or is not seen to be pathological. That complexity about fluxing external impacts on health, internal consequences and normative scenarios can only be respected if current reductionist neuroscience is challenged. It would be replaced by a different open systems version that respectfully understands the biological processes that exist within in our particular social and biographical contexts. Those processes afford us our ability to act as reflective and efficient moral agents but our conduct will never be reducible to them.

If we stay with the position that human conduct and experience are expressions of causal patterns which are interactive (i.e. they might be synergistic additive or antagonistic), and we remind ourselves that agency shapes and is shaped by the 
particularities of the open system we inhabit, then biology and society can be appreciated as a co-constituted whole. However, contra the EBP statement noted earlier, we need to understand open complexity not experimentally manipulated single closed loops.

This has profound methodological implications for open systems mental health research and resonates with why the founders of general systems theory (Paul Weiss and Ludwig Von Bertalanffy) wanted to leave the laboratory to study reallife situations. In the latter, we look for generative mechanisms operating contingently, we do not seek to draw possible causal conclusions from correlational studies in which many relevant potential sources of influence have been controlled out. The latter phrase is a deliberately negative and critical way of thinking about the rhetoric of experimental neuroscience and the facts it purports to generate. The hoped-for-reductionism within psychiatry, from Freud to Insel, is doomed to failure. However, an interactionist approach to neuroscience, in which we are viewed not as carriers of human brains, which cause our behaviour, but moral agents operating in fluid normative social context, which both affect, and are affected by, our conduct remains a positive prospect. [For a further exploration of this prospect see Pitt-Taylor (2016)].

\section{Conclusion}

From a CR perspective both personal experience and neuroscience are important but so too is the way we approach them. The axiom of ontological realism requires that for social scientists, biological not just social factors are important to understand. However, we must be careful not to fall into the trap of positivist neuroscience, which limits our attention to the closed system of 'brain and behaviour' reductions. The axiom of epistemological relativism is also important, but subjectively reported experience does not exhaust our quest for understanding complexity: our personal accounts are neither a full window into the society we are embedded in, nor into the bodily reality that shapes and constrains our humanity, experience, morbidity and mortality. However, they are important reflexive testimonies about that complexity. They are part of the picture that should neither be sacralised nor scorned.

This article, using critical realism as a philosophical resource, began with the importance of rhetorical positions in mental health debates. It moved to the strengths and limitations of using the biopsychosocial model and then to appraising two versions of neuroscience. Only one version of the latter offers us the prospect of respecting human agents, in their particular social contexts, and understanding the complexity of the causes and meanings associated with wellbeing, distress, unintelligibility or incorrigibility. Traditionally and understandably sociologists have been wary of biological explanations for human experience and behaviour. However, the dialogue between the two academic traditions should remain open and constructive. That dialogue might help us all to avoid 
neuro-reductionism and it might enable neuroscientists to understand better the role of both human agency and social determinism in their work.

\section{References}

Anda, R., B. Felliti, J.D. Bremner, J. Walker, C. Whitfield, and B. Perry. 2006. The Enduring Effects of Abuse and Related Adverse Experiences in Childhood: A Convergence of Evidence from Neurobiology and Epidemiology. European Archives of Psychiatry and Clinical Neuroscience 265 (3): $174-186$.

Angell, M. 2011. The Illusions of Psychiatry. Review of Books. New York.

Archer, M. 1997. Realist Social Science: The Morphogenetic Approach. Cambridge: Cambridge University Press.

Archer, M. 2000. Being Human: The Problem of Agency. Cambridge: Cambridge University Press.

Benton, T. 1991. Biology and Social Science: Why the Return of the Repressed Should be Given a (Cautious) Welcome. Sociology 25 (1): 63-68.

Bhaskar, R. 2016. Enlightened Common Sense: The Philosophy of Critical Realism. London: Routledge.

Bhaskar, R., and B. Danermark. 2006. Metatheory, Interdisciplinarity and Disability Research: A Critical Realist Perspective. Scandinavian Journal of Disability Research 4: 278-297.

Breggin, P., and G. Breggin. 1994. Talking Back to Prozac. New York: St Martin's Press.

Broad, C.D. 1925. The Mind and Its Place in Nature. London: Routledge \& Kegan Paul.

Campbell, P., and D. Rose. 2011. Action for Change in the UK: Thirty Years of The user/Survivor Movement. In The SAGE Handbook of Mental Health and Illness, ed. D. Pilgrim, A. Rogers, and B. Pescosolido. London: Sage.

Clayton, P., and P. Davies. 2006. The Re-emergence of Emergence. Oxford: Oxford University Press.

Cutajar, M.C., P.E. Mullen, J.R.P. Ogloff, S.D. Thomas, D.L. Wells, and J. Spataro. 2010. Psychopathology in a Large Cohort of Sexually Abused Children Followed up to 43 Years. Child Abuse and Neglect 34 (11): 813-822.

De Groot, M., S.H. Golden, and J. Wagner. 2016. Psychological Conditions in Adults with Diabetes. American Psychologist 71: 552.

Dennett, D. 1984. Elbow Room. Cambridge: MIT Press.

Engel, G. 1977. The Need for a New Medical Model: A Challenge for Biomedicine. Science 196 (4286): 129-136.

Engel, G.L. 1980. The Clinical Application of the Biopsychosocial Model. American Journal of Psychiatry 137: 535-544.

Erickson, K., C. Hillman, and A. Kramer. 2015. Physical Activity, Brain, and Cognition. Current Opinion in Behavioral Sciences. 4: 27-32.

Fitzgerald, D., N. Rose, and I. Singh. 2016. Revitalizing Sociology: Urban Life and Mental Illness Between History and the Present. British Journal of Sociology 67 (1): 138-160.

Flatschart, E. 2017. Feminist Standpoints and Critical Realism: The Contested Materiality of Difference in Intersectionality and New Materialism. Journal of Critical Realism 16 (3): 284-302.

Frances, A. (2010) Opening Pandora's Box: The 19 worst suggestions for DSM-5. Psychiatric Times.

Fullagar, S. 2009. Negotiating the Neurochemical Self: Anti-depressant Consumption in Women's Recovery from Depression. Health 13: 389-406.

Galea, S., M. Uddin, and K. Koenen. 2011. The Urban Environment and Mental Disorders: Epigenetic Links'. Epigenetics 6 (4): 400-404.

Garcia-Toro, M., and I. Auirre. 2007. Biopsychosocial Model in Depression. Medical Hypotheses 68 (3): 683-691.

Guze, S.B. 1989. Biological Psychiatry: Is There Any Other Kind? Psychological Medicine 19: 315-323.

Harré, R. 2002. Cognitive Science: A Philosophical Introduction. London: Sage.

HBP-PS Consortium. 2012. The Human Brain Project: A Report to the European Commission. Lausanne: The HBP-PS Consortium.

Healy, D. 2004. Psychopathology at the Interface Between the Market and the New Biology. In The New Brain Sciences: Perils and Prospects, ed. D. Rees and S. Rose. Cambridge: Cambridge University Press. 
Herzberg, D. 2009. Happy Pills in America: From Miltown to Prozac. Baltimore: Johns Hopkins University Press.

Higgs, P., J.R. Jones, and G. Scambler. 2004. Class as Variable, Class as Generative Mechanism: The Importance of Critical Realism for the Sociology of Health Inequalities. In Making Realism Work: Realist Theory and Empirical Research, ed. B. Carter and C. New, 52-63. London: Routledge.

Illlich, I. 1977. Medical Nemesis. London: Marion Boyars.

Johnstone, L., and L. Dallos. 2006. Formulation in Psychology and Psychotherapy: Making Sense of People's Problems. London: Taylor \& Francis.

Jones, E.G., and L.M. Mendell. 1999. Assessing the 'Decade of the Brain'. Science 284 (5415): 739.

Kingdon, D., and A.H. Young. 2007. Research into Putative Biological Mechanisms of Mental Disorders has been of No Value to Clinical Psychiatry. British Journal of Psychiatry 191 (4): 285-290.

Kirsch, I. 2009. The Emperor's New Drugs: Exploding the Antidepressant Myth. New York: Random House.

Lakoff, A. 2005. Pharmaceutical Reason: Knowledge and Values in Global Psychiatry. Cambridge: Cambridge University Press.

Landecker, H., and A. Panofsky. 2013. From Social Structure to Gene Regulation, and back: A Critical Introduction to enviRonmental Epigenetics for Sociology. Annual Review of Sociology 39 (1): 333-357.

Lederbogen, F., P. Kirsch, L. Haddad, et al. 2011. City Living and Urban Upbringing Affect Neural Social Stress Processing in Humans. Nature 474: 498-501.

Lemert, C. 1980. Sociology and the Twilight of Man. Carbondale: Southern Illinois University Press.

Margolis, J. 1990. Reconciling Realism and Relativism. In The Rhetorical Turn: Invention and Persuasion in the Conduct of Inquiry, ed. H. Simons. Chicago: Chicago University Press.

Meyer, A. 1952. The Collected Works of Adolf Meyer. New York: Basic Books.

Mingers, J. 2011. The Contribution of Systemic Thought to Critical Realism. Journal of Critical Realism 10 (3): 303-330.

Moncrieff, J. 2008. The Myth of the Chemical Cure. Basingstoke: Palgrave.

Pilgrim, D. 2007. The Survival of Psychiatric Diagnosis. Social Science and Medicine 65 (3): 536-544.

Pilgrim, D. 2008. The Eugenic Legacy in Psychology and Psychiatry. International Journal of Social Psychiatry 54 (3): 272-284.

Pilgrim, D. 2015a. Understanding Mental Health: A Critical Realist Exploration. London: Routledge.

Pilgrim, D. 2015b. The Biopsychosocial Model in Health Research: Its' Strength and Limitations for Critical Realists. Journal of Critical Realism 14 (2): 164-180.

Pitt-Taylor, V. 2016. The Brain's Body: Neuroscience and Corporeal Politics. London: Duke University Press.

Read, J. 2005. The Bio-Bio-Bio Model of Madness. The Psychologist 18 (40): 596-597.

Read, J., R. Fosse, A. Moskowitz, and B. Perry. 2014. The Traumagenic Neurodevelopmental Model of Psychosis Revisited. Neuropsychiatry 4 (1): 64-79.

Rose, N. 1990. Governing the Soul. London: Routledge.

Rose, N. 2013. The Human Sciences in a Biological Age. Theory, Culture and Society 30 (1): 3-34.

Rose, D. 2017. Service User/Survivor-Led Research in Mental Health: Epistemological Possibilities. Disability and Society 32 (6): 773-789.

Rose, S., and H. Rose. 2012. Genes, Cells and Brains: Bioscience's Promethean Promises. London: Verso.

Rosenfield, S. 2012. Triple jeopardy? Mental Health at the Intersection of Gender, Race, and Class. Social Science and Medicine 74 (1): 1791-1796.

Sarewitz, D., and R. Nelson. 2008. Three Rules for Technological Fixes. Nature 456: 871-872.

Schilling, E.A., R.H. Aseltine, and S. Gore. 2008. The Impact of Cumulative Childhood Adversity on Young Adult Mental Health: Measures, Models, and Interpretations. Social Science and Medicine 6 (5): 1140-1151.

Sedgwick, P. 1982. Psychopolitics. London: Pluto Press.

Simons, H. 1990. The Rhetorical Turn: Invention and Persuasion in the Conduct of Inquiry. Chicago: Chicago University Press.

Skinner, B.F. 1971. Beyond Freedom and Dignity. New York: Alfred A. Knopf Inc.

Tallis, R. 2011. Aping Mankind: Neuromania, Darwinitis and the Misrepresentation of Humanity. London: Acumen.

Tortorello, F. 2017. What is Real About Reductive Neuroscience? Journal of Critical Realism 16 (3): 235-254. 
Varela, C.R. 2003. Biological Structure and Embodied Human Agency: The Problem of Instinctivism. Journal for the Theory of Social Behaviour 33 (1): 95-122.

Whitaker, R. 2010. Anatomy of an Epidemic. New York: Broadway Press.

Williams, S. 1999. Is Anybody There? Critical Realism, Chronic Illness and the Disability Debate. Sociology of Health and Illness 21: 797-819.

Wittchen, H., F. Jacobi, et al. 2011. The Size and Burden of Mental Disorders and Other Disorders of the Brain in Europe 2010. European Neuropsychopharmacology 21 (9): 655-679.

Wolman, B.B. 1981. Contemporary Theories and Systems in Psychology. Amsterdam: Plenum.

Wykes, T., and F. Callard. 2010. Diagnosis, Diagnosis, Diagnosis: Towards DSM-5. Journal of Mental Health 19 (4): 301-304.

Yates, A. 1970. Behavior Therapy. New York: Wiley.

Publisher's Note Springer Nature remains neutral with regard to jurisdictional claims in published maps and institutional affiliations.

David Pilgrim, PhD, is Honorary Professor of Health and Social Policy at the University of Liverpool and Visiting Professor of Clinical Psychology at the University of Southampton. He trained and worked in the NHS as a clinical psychologist before completing a PhD in psychology and then a Masters in sociology. With this mixed background, his career was split then between clinical and academic work as a health policy researcher. His publications include Understanding Mental Health: A Critical Realist Exploration (Routledge, 2015) and Key Concepts in Mental Health (4th edition, Sage, 2017). Others include A Sociology of Mental Health and Illness (Open University Press, 2005-winner of the 2006 BMA Medical Book of the Year Award), Mental Health Policy in Britain (Palgrave, 2002) and Mental Health and Inequality (Palgrave, 2003) (all with Anne Rogers). His most recent book, Child Sexual Abuse: Moral Panic or State of Denial?, is published by Routledge. All of this work is approached from the position of critical realism and so the philosophy of science and social science is an overarching framework in relation to any topic. 